\title{
Core genome components and lineage specific expansions in malaria parasites Plasmodium
}

\author{
Hong Cai ${ }^{1 \dagger}$, Jianying $\mathrm{Gu}^{2 \dagger}$, Yufeng Wang ${ }^{1,3^{*}}$ \\ From The ISIBM International Joint Conference on Bioinformatics, Systems Biology and Intelligent Comput- \\ ing (IJCBS) \\ Shanghai, China. 3-8 August 2009
}

\begin{abstract}
Background: The increasing resistance of Plasmodium, the malaria parasites, to multiple commonly used drugs has underscored the urgent need to develop effective antimalarial drugs and vaccines. The new direction of genomicsdriven target discovery has become possible with the completion of parasite genome sequencing, which can lead us to a better understanding of how the parasites develop the genetic variability that is associated with their response to environmental challenges and other adaptive phenotypes.

Results: We present the results of a comprehensive analysis of the genomes of six Plasmodium species, including two species that infect humans, one that infects monkeys, and three that infect rodents. The core genome shared by all six species is composed of 3,351 genes, which make up about $22 \%-65 \%$ of the genome repertoire. These components play important roles in fundamental functions as well as in parasite-specific activities. We further investigated the distribution and features of genes that have been expanded in specific Plasmodium lineage(s). Abundant duplicate genes are present in the six species, with 5\%-9\% of the whole genomes composed lineage specific radiations. The majority of these gene families are hypothetical proteins with unknown functions; a few may have predicted roles such as antigenic variation.
\end{abstract}

Conclusions: The core genome components in the malaria parasites have functions ranging from fundamental biological processes to roles in the complex networks that sustain the parasite-specific lifestyles appropriate to different hosts. They represent the minimum requirement to maintain a successful life cycle that spans vertebrate hosts and mosquito vectors. Lineage specific expansions (LSEs) have given rise to abundant gene families in Plasmodium. Although the functions of most families remain unknown, these LSEs could reveal components in parasite networks that, by their enhanced genetic variability, can contribute to pathogenesis, virulence, responses to environmental challenges, or interesting phenotypes.

\section{Background}

Malaria affects approximately 300 million people worldwide and kills between 1 and 1.5 million people every year. It has been largely controlled by effective medicines until recently, but malaria parasites have gradually developed resistance to multiple drugs and pose an increasingly important health threat.

\footnotetext{
* Correspondence: yufeng.wang@utsa.edu

+ Contributed equally

'Department of Biology, University of Texas at San Antonio, San Antonio, TX 78249, USA

Full list of author information is available at the end of the article
}

The causative agents of malaria are protozoan parasites in the genus Plasmodium. Four species of Plasmodium cause malaria in humans: Plasmodium falciparum, P.vivax, P. ovale, and P. malaria. P. falciparum is the most widespread and devastating one; if untreated it can be fatal. Other species from this genus are known to infect rodents and non-human primates.

The complete sequencing of various malaria parasite genomes has brought new hope for the discovery of new antimalarial targets [1-5]. Before the genome of $P$. falciparum was sequenced, only about 20 proteins had been characterized. Genome sequencing revealed 
over 5,400 open reading frames (ORFs) in P. falciparum. Successful application of the genomic analysis approach has already lead to the discovery of potential vaccine targets such as $P$. falciparum erythrocyte membrane protein families (PfEMPs) [6,7] and drug targets such as a 1-deoxy-D-xylulose 5-phosphate (DOXP) reductoisomerase [8] and a catalog of proteases that may play important roles in parasite development and invasion [9-11]. Comparative genomics has also shed significant light on the mechanisms of drug resistance involving transporter proteins [12]. The release of the genome data has also made it possible to carry out large scale expression analysis at the transcriptome and proteome levels. Microarray and proteomic experiments have revealed interesting expression patterns of gene products under specific temporal and spatial conditions [13-19], providing a blueprint for a systems level study of gene regulatory networks, protein-protein networks and metabolic networks [20-22], and representing the beginning of a new era of systems biology in malaria research.

Within the scheme of systems biology, one of the interesting questions is how parasites develop genetic variability that can be tied to their response to environmental challenges and other adaptive phenotypes.

In this study, we propose to explore the genome context and systems evolution of six model species of Plasmodium: P.falciparum and P. vivax are the model system for human parasites, and cause the first and second most severe forms of human malaria; P. knowlesi used to be considered as a model system for the simian parasite whose natural mammalian host is the Macaque monkey, however, increasing evidence shows that naturally occurring $P$. knowlesi-induced human malaria is not rare [5,23]; P. yoelii yoelii, $P$. berghei, and $P$. chabaudi are the model systems of rodent parasites which have been used widely and successfully to complement research on human malaria parasites.

We focus on two fundamental questions: (1) What are the common components in these six malaria parasites? As they all have evolved a successful parasite lifestyle, the core genome structure may reveal critical adaptive features. (2) What are the lineage specific components in each species? In particular, we are interested in genes or gene families that have been largely expanded in one or several unique lineages. We show that the core genome and lineage-specific expanded genome components involve genes that are tied to pathogenesis and virulence mechanisms as well as in the fundamental life cycle of Plasmodium species.

\section{Results and discussion}

\section{The core genome of six Plasmodium species}

\section{(1) The core genome is comprised of 3,351 othologous} genes

The orthoMCL analysis revealed that the core genome of the six Plasmodium species we examined is comprised of 3,351 othologous genes (Table 1). The catalog of the core genome is summarized in Additional file 1. The proportions of core genome components in the two human malaria parasites ( $P$. falciparum and $P$. vivax) were very similar (approximately 61\%). The simian parasite $P$. knowlesi has a slightly larger genome and a higher proportion of the core genome (66\%). The three rodent species seem to have more diverse genomes; only about $22-42 \%$ of the genes encode core components. The numbers of the predicted ORFs in the $P$. berghe $i$ genome $(12,235)$ and in the $P$. chabaudi genome $(15,007)$ are relatively larger than those in the other four species due to the fragmented nature of the sequence data and incomplete annotation of these genomes [17], therefore results for these species must be seen as preliminary.

Interestingly, 1,079 (33\%) of the 3,351 orthologous clusters in the core genome were predicted to fall into at least one Gene Ontology class, while the remaining $2,272(67 \%)$ appear to have no identifiable ontology functions. This is consistent with the fact that at least $60 \%$ of the 5,460 ORFs in the best-annotated Plasmodium species, $P$. falciparum, were annotated as "hypothetical protein", indicating that no reliable functional prediction/characterization was available [4].

(2) Core genome components involved in fundamental biological processes in Plasmodium

Despite their different host specificities, the six Plasmodium species preserve the common components that are essential for their fundamental biology (see examples in Table 2).

Abundant orthologous families are involved in genetic information processing: replication, transcription and translation. None of these processes in malaria parasites are fully understood. For example, it is believed that the transcriptional regulation of malaria parasites is very complex, as it must adapt to different developmental processes in their vertebrate hosts and invertebrate mosquito vectors such as sexual development, parasite invasion, and antigenic variation. However, to date, only a small number of general transcription factors have been identified [24]. Recently, microarray expression and machine learning approaches have revealed putative cisregulatory promoters that may be associated with specific transcription factors $[25,26]$. The core genome of 
Table 1 The core genome components and lineage specific genes in six Plasmodium species. The inter-genomic search yielded a core genome comprised of 3,351 orthologous proteins

\begin{tabular}{lcccccc}
\hline \multicolumn{1}{c}{ Strains } & No. Genes in genome & \% core in genome & \multicolumn{2}{c}{ No. Families with LSE } & No. LSE genes & \% LSEs in genome \\
\cline { 3 - 5 } & & & Lineage-unique & Typical LSE & & \\
\hline P. berghei & 12,235 & 27.39 & 111 & 323 & 960 & 7.84 \\
P. chabaudi & 15,007 & 22.33 & 176 & 379 & 1342 & 8.94 \\
P. falciparum & 5,460 & 61.37 & 36 & 13 & 510 & 9.34 \\
P. knowlesi & 5,110 & 65.57 & 12 & 14 & 293 & 5.73 \\
P. vivax & 5,432 & 61.69 & 45 & 21 & 488 & 8.98 \\
P. yoelii yoelii & 7,861 & 42.63 & 62 & 65 & 553 & 7.03 \\
\hline
\end{tabular}

these six Plasmodium species suggests that the basic transcriptional machinery includes the essential enzymes, general transcription factors, and positive and negative transcriptional cofactors. Similarly, the common elements of the translational machinery are also present in the core genome, including orthologous clusters that regulate the initiation, elongation, and termination of the processes. Associated with translation, we also observe that the RNA splicesome is conserved in the six Plasmodium genomes: orthologous clusters are predicted to belong to the $\mathrm{GO}$ classes of small nucleolar ribonucleoprotein complex (GO:0005732), spliceosome assembly (GO:0000245), RNA splicing factor activity, transesterification mechanism (GO:0031202), spliceosome (GO:0005681), snRNP U1 (GO:0005685), and snRNP U2 (GO:0005686). The core genome also includes components that are essential for repair mechanisms and cell motion.

(3) Core genome components involved in cellular processes related to the parasite lifestyle

In addition to the genes or gene products that are required for fundamental biology, we are particularly interested in the core genome components that are pertinent to parasite-specific lifestyles. Representative functional classes of orthologous clusters are shown in Table 3.

One of the most important cellular processes that are critical for a successful life cycle in malaria parasites is cell cycle regulation. During the red blood cell stage, malaria parasites undergo atypical cell cycles. The entire genetic regulatory network of the cell cycle remains largely unknown [27-29]. Previously, we proposed a cell cycle network composed of 38 components using a Variational Bayesian expectation maximization (VBEM) approach based on comparative genomic prediction and microarray time-series expression profile [30]. This study confirmed that fifteen of the orthologous clusters in the Plasmodium core genome are members of the cell cycle network. For example, ORTHOMCL1356 and ORTHOMCL2659 may both be involved in cyclindependent kinase regulation (Table 3). The next step will be to place these orthologous genes in a network context.

In addition to the cell cycle, signal transduction also plays a role in other cellular networks. For example, at least one orthologous cluster (ORTHOMCL3024) is found in all six Plasmodium species and may participate in a G-protein coupled receptor (GPCR) protein signaling pathway. GPCRs have been attractive therapeutic targets for human diseases due to their versatile and critical roles in many signal transduction pathways. However, to date, no GPCR homolog has been identified in a Plasmodium genome, although Rab GTPases are found in the $P$. falciparum genome [4]. The core component ORTHOMCL3024 encodes a receptor for an activated C kinase homolog, named pfRACK, in P. falciparum. It has a single homolog in the other five Plasmodium species, all of which contain guanine nucleotide-binding motifs. It has been shown that pfRACK mRNA is expressed throughout the 48-hour red blood cell (RBC) cycle $[13,19]$, and its protein product has been found in red blood cell membrane, and in the merozoite and trophozoite stages of the RBC cycle in several independent proteomics experiments $[15,16]$. Notably, it was previously reported that signaling via human erythrocytic GPCR regulated the entry of malaria parasites and a GPCR inhibitor blocked malaria infection [31], which makes GPCR agonists potential antimalarial targets. The existence of parasite proteins that may be involved in GPCR-like activities suggests that other parasite signaling proteins may be associated with host proteins to contribute to the parasite entry process.

Parasites, during their complex life cycles, also need to meet the challenges from various environmental signals. At least 23 orthologous clusters that play a role in the parasite responses to heat and stress, such as oxidative stress, are commonly shared in the six Plasmodium species.

Moreover, the core genome contains orthologous clusters that may be relevant to pathogenesis or virulence. Four othologous clusters (ORTHOMCL106, ORTHOMCL15, ORTHOMCL2196, ORTHOMCL2303) 
Table 2 The core genome components in six Plasmodium species involved in fundamental cellular processes

\begin{tabular}{|c|c|c|}
\hline Function description & Examples of GO classes & Orthologous families \\
\hline \multirow[t]{15}{*}{ Replication } & GO:0003688 (DNA replication origin binding) & ORTHOMCL1162 \\
\hline & & ORTHOMCL2123 \\
\hline & GO:0003887 (DNA-directed DNA polymerase activity) & ORTHOMCL2751 \\
\hline & & ORTHOMCL61 \\
\hline & & ORTHOMCL2153 \\
\hline & & ORTHOMCL593 \\
\hline & & ORTHOMCL2507 \\
\hline & GO:0005663 (DNA replication factor C complex) & ORTHOMCL1738 \\
\hline & & ORTHOMCL1861 \\
\hline & & ORTHOMCL443 \\
\hline & & ORTHOMCL513 \\
\hline & & ORTHOMCL1911 \\
\hline & & ORTHOMCL2437 \\
\hline & & ORTHOMCL3328 \\
\hline & GO:0005662 (DNA replication factor A complex) & ORTHOMCL683 \\
\hline \multirow[t]{12}{*}{ Transcription } & GO:0000122 (negative regulation of transcription from RNA polymerase II promoter) & ORTHOMCL190 \\
\hline & GO:0000126 (transcription factor TFIIIB complex) & ORTHOMCL2349 \\
\hline & & ORTHOMCL802 \\
\hline & GO :0016251 (general RNA polymerase II transcription factor activity) & ORTHOMCL2179 \\
\hline & GO:0003702 (RNA polymerase II transcription factor activity) & ORTHOMCL1522 \\
\hline & & ORTHOMCL3420 \\
\hline & GO:0003712 (transcription cofactor activity) & ORTHOMCL3015 \\
\hline & GO:0003700 (transcription factor activity) & ORTHOMCL1875 \\
\hline & & ORTHOMCL3398 \\
\hline & & ORTHOMCL880 \\
\hline & & ORTHOMCL2851 \\
\hline & & ORTHOMCL2947 \\
\hline \multirow[t]{22}{*}{ Translation } & GO:0006412 (translation) & ORTHOMCL1544 \\
\hline & & ORTHOMCL3343 \\
\hline & & ORTHOMCL1471 \\
\hline & & ORTHOMCL1516 \\
\hline & & ORTHOMCL1698 \\
\hline & & ORTHOMCL2550 \\
\hline & & ORTHOMCL1856 \\
\hline & GO:0003743 (translation initiation factor activity) & ORTHOMCL1832 \\
\hline & & ORTHOMCL1842 \\
\hline & & ORTHOMCL2705 \\
\hline & & ORTHOMCL3178 \\
\hline & & ORTHOMCL2122 \\
\hline & & ORTHOMCL940 \\
\hline & & ORTHOMCL3423 \\
\hline & GO:0003746 (translation elongation factor activity) & ORTHOMCL350 \\
\hline & & ORTHOMCL1193 \\
\hline & & ORTHOMCL2152 \\
\hline & & ORTHOMCL2232 \\
\hline & & ORTHOMCL1803 \\
\hline & & ORTHOMCL516 \\
\hline & & ORTHOMCL1744 \\
\hline & GO:0006449 (regulation of translational termination) & ORTHOMCL2253 \\
\hline
\end{tabular}


Table 2 The core genome components in six Plasmodium species involved in fundamental cellular processes (Continued)

\begin{tabular}{|c|c|c|}
\hline \multirow[t]{5}{*}{ Repair } & GO:0006289 (nucleotide-excision repair) & ORTHOMCL444 \\
\hline & GO:0000724 (double-strand break repair via homologous recombination) & ORTHOMCL1863 \\
\hline & GO:0006302 (double-strand break repair) & ORTHOMCL867 \\
\hline & GO:0006281 (DNA repair) & ORTHOMCL543 \\
\hline & & ORTHOMCL1058 \\
\hline \multirow[t]{10}{*}{ Cell motion } & GO:0007017 (microtubule-based process) & ORTHOMCL2981 \\
\hline & & ORTHOMCL1078 \\
\hline & GO:0003777 (microtubule motor activity) & ORTHOMCL2241 \\
\hline & & ORTHOMCL2737 \\
\hline & GO:0007018 (microtubule-based movement) & ORTHOMCL1635 \\
\hline & & ORTHOMCL2737 \\
\hline & & ORTHOMCL1944 \\
\hline & GO:0030048 (actin filament-based movement) & ORTHOMCL278 \\
\hline & & ORTHOMCL1146 \\
\hline & & ORTHOMCL428 \\
\hline
\end{tabular}

may be related to the host cell entry process. For example, ORTHOMCL106 includes 3 copies of Merozoite Surface Protein 7 (MSP7) precursor homologs (accession numbers MAL13P1.173, MAL13P1.174, and PF13_0197), and one hypothetical protein (PF13_0191) in P. falciparum. These four genes are tandemly located at adjacent positions in the same direction on Chromosome 13. They all seem to code for antigenic epitopes, and the three MSP7-like proteins were all expressed at the RBC surface [15]. MSP7 was reported to be expressed at the merozoite surface and associated with the MSP1 complex shed during RBC invasion [32]. Various copies of MSP7 homologs are present in other species (1 in P. berghei, P. knowlesi, P. yoelii yoelii, 2 in $P$. chabaudi, 3 in $P$. vivax), suggesting that RBC entry requires similar surface proteins in all species.

ORTHOMCL2797 is another orthologous cluster that is predicted to be related to pathogenesis. It encodes a transmission-blocking target antigen s230 precursor (Pfs230) in P. falciparum and one single copy is present in the other five Plasmodium species. Pfs230 is expressed on the plasma membrane of parasite gametocytes in the human host and, after the parasites are taken up in a blood meal by a mosquito vector, it remains on the surface of the emerged gamete [33]. Transmission activity was found to be blocked when anti-Pfs230 antibodies were used, suggesting Pfs230 can be a potential vaccine target.

Two orthologous clusters might be related to the parasite's response to drugs. ORTHOMCL3437 contains one copy of chloroquine resistance transporter in each Plasmodium species; ORTHOMCL780 contains one copy of a multidrug resistance protein in five Plasmodium species, and 2 copies in $P$. chabaudi.
Lineage specific expansions (LSEs) in Plasmodium species The comparative genomic analysis of six Plasmodium species revealed genes that are specifically expanded in certain lineage(s). The emergence of multiple gene copies by duplication or lateral gene transfer in a specific lineage is known as a lineage specific expansion (LSE) event. Gene duplication has long been considered as a driving force for functional novelty as the duplicate copy can serve as a shield for the other copy with otherwise deleterious mutations to evolve novel functions under relaxed evolutionary constraints [34]. Parasites can also acquire new genes from other organisms via lateral gene transfer. The subsequent expansion of these new genes can increase the number of gene copies. LSEs are believed to be of critical importance to the evolution of genome plasticity as they provided opportunities for functional redundancy which could lead to the emergence of new functions [35].

A large number of duplicate genes have been identified in Plasmodium. Among them, abundant genes exhibit lineage specific expansions, accounting for approximately $5 \%-9 \%$ of the whole genomes (see Table 1 for the summary, and also see Additional file 2 for the detailed gene lists), suggesting that these parasite genomes have undergone frequent gene duplications that may confer advantages in selection. Two human malaria parasites, $P$.falciparum and $P$. vivax possess the largest proportion of LSEs. Three rodent parasite species $P$. berghei, $P$. chabaudi and $P$. yoelii yoelii have slightly smaller proportion of LSE genes than the human parasites, ranging from $7.03 \%-8.94 \%$. P. knowlesi, however, contains significantly smaller number of duplicate genes, compared to the other five sibling species. 
Table 3 Representative cellular processes related to parasite specific lifestyle that are commonly present in six Plasmodium genomes

\begin{tabular}{|c|c|c|}
\hline Function description & Examples of GO classes & Orthologous families \\
\hline \multirow[t]{14}{*}{ Cell Cycle } & \multirow[t]{2}{*}{ GO:0000079 (Regulation of cyclin-dependent protein kinase activity) } & ORTHOMCL1356 \\
\hline & & ORTHOMCL2659 \\
\hline & \multirow[t]{8}{*}{ GO:0051726 (regulation of cell cycle) } & ORTHOMCL703 \\
\hline & & ORTHOMCL2129 \\
\hline & & ORTHOMCL2139 \\
\hline & & ORTHOMCL3332 \\
\hline & & ORTHOMCL93 \\
\hline & & ORTHOMCL 1497 \\
\hline & & ORTHOMCL2030 \\
\hline & & ORTHOMCL3034 \\
\hline & GO:0045836 (positive regulation of meiosis) & ORTHOMCL1572 \\
\hline & \multirow[t]{2}{*}{ GO:0007049 (cell cycle) } & ORTHOMCL3532 \\
\hline & & ORTHOMCL1160 \\
\hline & GO:0000082 (G1/S transition of mitotic cell cycle) & ORTHOMCL3162 \\
\hline \multirow[t]{8}{*}{ Signal transduction } & GO:0007266 (Rho protein signal transduction) & ORTHOMCL2354 \\
\hline & \multirow[t]{5}{*}{ GO:0007165 (signal transduction) } & ORTHOMCL3462 \\
\hline & & ORTHOMCL3526 \\
\hline & & ORTHOMCL3426 \\
\hline & & ORTHOMCL1645 \\
\hline & & ORTHOMCL710 \\
\hline & GO:0007186 (G-protein coupled receptor protein signaling pathway) & ORTHOMCL3024 \\
\hline & GO:0008426 (protein kinase C inhibitor activity) & ORTHOMCL2343 \\
\hline \multirow[t]{23}{*}{ Response to environmental challenges } & \multirow[t]{9}{*}{ GO:0006979 (response to oxidative stress) } & ORTHOMCL2680 \\
\hline & & ORTHOMCL602 \\
\hline & & ORTHOMCL2542 \\
\hline & & ORTHOMCL1549 \\
\hline & & ORTHOMCL2530 \\
\hline & & ORTHOMCL1476 \\
\hline & & ORTHOMCL3291 \\
\hline & & ORTHOMCL3446 \\
\hline & & ORTHOMCL2315 \\
\hline & GO:0006950 (response to stress) & ORTHOMCL3208 \\
\hline & \multirow[t]{13}{*}{ GO:0009408 (response to heat) } & ORTHOMCL2452 \\
\hline & & ORTHOMCL2633 \\
\hline & & ORTHOMCL112 \\
\hline & & ORTHOMCL237 \\
\hline & & ORTHOMCL702 \\
\hline & & ORTHOMCL803 \\
\hline & & ORTHOMCL1088 \\
\hline & & ORTHOMCL1813 \\
\hline & & ORTHOMCL3347 \\
\hline & & ORTHOMCL1486 \\
\hline & & ORTHOMCL2019 \\
\hline & & ORTHOMCL3266 \\
\hline & & ORTHOMCL700 \\
\hline
\end{tabular}


Table 3 Representative cellular processes related to parasite specific lifestyle that are commonly present in six Plasmodium genomes (Continued)

Pathogenesis

\begin{tabular}{ll} 
GO:0009405 (pathogenesis) & ORTHOMCL2797 \\
\hline GO:0030260 (entry into host cell) & ORTHOMCL106 \\
& ORTHOMCL15 \\
& ORTHOMCL2196 \\
\hline GO:0042493 (response to drug) & ORTHOMCL2303 \\
\hline GO:0020035 (cytoadherence to microvasculature, mediated by parasite protein) & ORTHOMCL3437 \\
& ORTHOMCL780 \\
\hline & ORTHOMCL261
\end{tabular}

We observed two distinct patterns of LSE gene families in the Plasmodium genomes: (1) lineage-unique LSEs, where genes are only duplicated in one unique genome and there is no orthologous gene in any other five genomes. (2) Typical LSEs that are formed from a gene for which at least one ortholog is found in at least one other of the genomes studied. Table 1 summarizes the distributions of these two types of LSEs in Plasmodium.

The lineage-unique gene families are likely to have more impacts on the genome because they carry species-specific signatures and appear to be "novel" within the pan-genome. Our further analyses focused on this group of LSEs. Two rodent parasites, $P$. chabaudi and $P$. berghei, have the largest numbers of lineage-specific LSEs (111 and 176, respectively); this may simply reflect the fact that these two genomes were predicted to have much larger number of ORFs.

The majority of these LSE families in Plasmodium contain only a small number ( $\leq 10$ copies) of genes (Figure 1). The gene family size ranges from two to 165 . In individual Plasmodium species, $28 \%-80 \%$ of the gene families are of size 2 , and, collectively, gene families of $2-4$ genes account for $60 \%-96 \%$ of the gene families. Large gene families are rare. The largest family is the rifin family in $P$. falciparum which has 165 paralogous members. Although the cellular function of rifins remains unknown, the antigenic variation in these proteins makes them vaccine candidates [36]. A recent phylogenetic and function shift analysis suggested that neofunctionalization and subfunctionilzation may have occurred during the rifin evolution [37]. Similarly, a complex evolutionary pattern is found in the second largest LSE in P. falciparum, erythrocyte membrane protein 1 (PfEMP1), another vaccine candidate which is proven responsible for antigenic variation and cytoadhesion of infected red blood cells [38,39].

It is extremely challenging to study the impact of LSEs in Plasmodium as most of these gene families are hypothetical proteins with unidentified functions - over $60 \%$ of the ORFs are annotated as hypothetical even in the best-studied P.falciparum genome [4]. For example, 85 out of 111 of the lineage-unique families in $P$. berghei

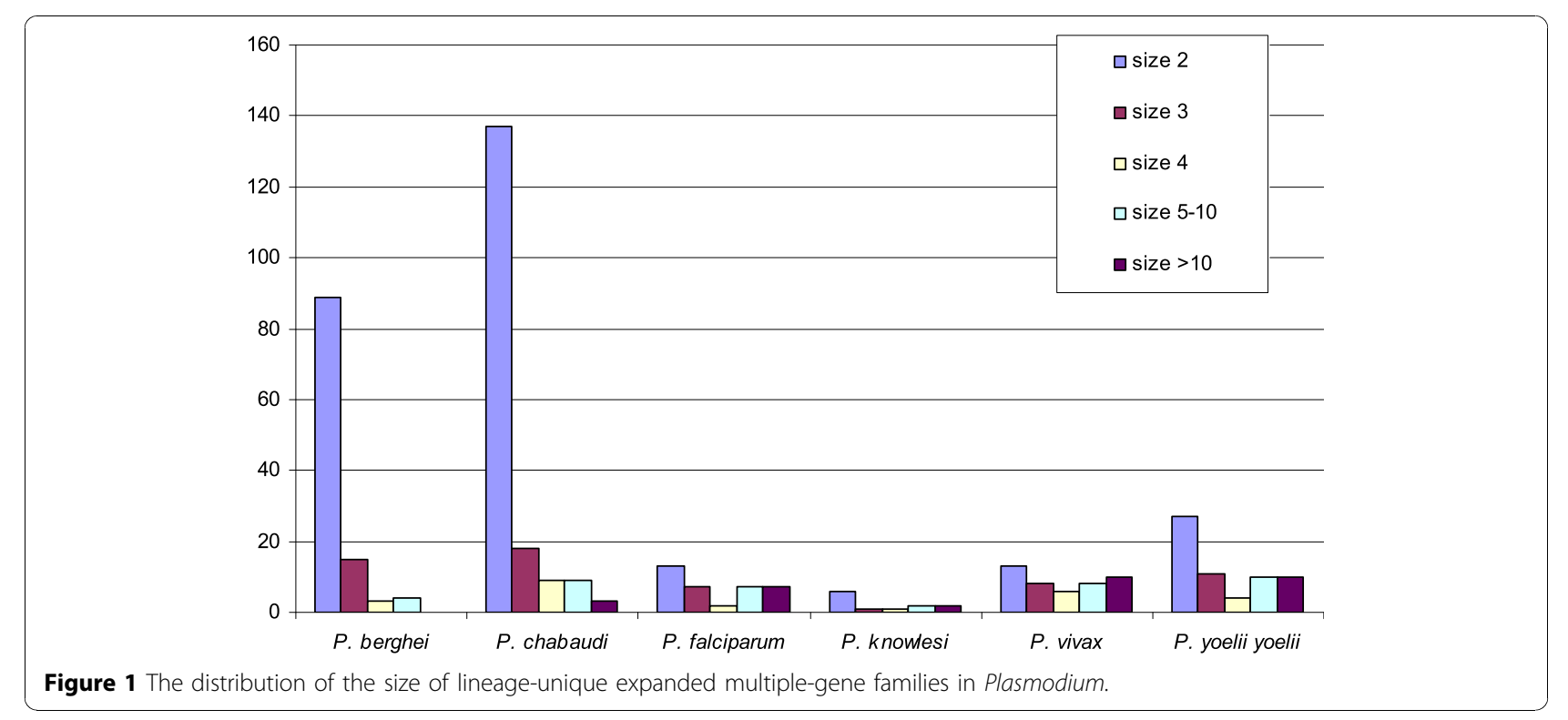


were predicted to be hypothetical, and the rest of them were predicted to be "putative", "Pb-fam" or "BIR protein", with none being functionally characterized. In the genome of $P$. chabaudi, several clusters of genes were annotated as "cyclin-related, putative", however, no clear evidence supports this prediction.

Some of the lineage-unique LSEs may carry out functions or have distinct antigenic features, which may be related to characteristics of the host organism that distinguish it from the other Plasmodium species. For example, vir genes, $P$. vivax variant genes coding for variant antigens exposed on $P$. vivax-infected reticulocytes, can be classified into several subgroups based on their sequence and structural diversity [40]. Although antigenic variation is common in Plasmodium species as a mechanism for parasites to evade the host immune system, different parasites appear to evolve different surface antigens with tissue-specific activities. Vir, for instance, is implicated in spleen-specific cytoadherence in chronic infections [41]. Similarly, a group of seven paralogous genes are found in P. knowlesi, forming SICAvar-like antigen, the simian specific surface antigen.

There are also remote homologs of genes with potential functions. For example, two paralogous genes (PFI0115c and PFI0120c) are likely to be products of a recent gene duplication event as they are tandemly located next to each other on chromosome 9. They are annotated as "Serine/Threonine protein kinase, FIKK family", however, there is only weak statistical support $(E$-score $=0.00035)$ for the presence of a kinase domain in a PFAM domain search. It is unclear whether there is indeed a kinase activity in these putative proteins.

\section{Conclusions}

Comparative genomic analysis of the six Plasmodium species with varying host specificity revealed 3,351 core genome components, whose functions range from fundamental biological processes to complex networks specific to a parasite-specific lifestyle. These core components represent the minimum requirement to maintain a successful life cycle that spans vertebrate hosts and mosquito vectors. They also include functionalities important to pathogenesis and adhesion to and invasion of host cells, indicating these six strains share a common mechanism for carrying out this phase of parasitic life cycle. Lineage specific expansions have given rise to abundant gene families in Plasmodium. Although functions of the majority of these families remain unknown, these LSEs could reveal components in parasite networks that, by their enhanced genetic variability, can be tied to pathogenesis, virulence, responses to environmental challenges, or interesting phenotypes.

\section{Methods}

Data

We collected the complete genomes of six Plasmodium species (Table 1) from PlasmoDB, the Plasmodium Genome resource center (http://www.plasmodb.org) [42]. The nucleotide, protein, and annotation data of Release 5.5 (September 29, 2008) were downloaded.

\section{Sequence similarity search and identification of orthologoues and paralogous families}

To identify the presence of orthologous and paralogous genes, we pooled all the protein sequences from the six Plasmodium genomes and conducted an exhaustive allagainst-all BLASTP search; genes were defined as orthologous or paralogous if (1) they had a FAST A E-score $<$ e-10; (2) their similarity I was $\geq 30 \%$ if the length of the alignable region $\mathrm{L} \geq 150$ amino acid residues (or $\mathrm{I}=$ $0.01 \mathrm{n}+4.8 \mathrm{~L}(-0.32(1+\exp (-\mathrm{L} / 1000)))$, if $\mathrm{L}<150$ aa, where $\mathrm{n}=$ the number of sequences); (3) the length of the alignable region between the two sequences was $>50 \%$ of the longer protein [43]; (4) Low complexity regions were filtered out.

A Markov cluster algorithm, OrthoMCL, was used to cluster genes into gene clusters [44]. The gene clusters contain the orthologous and paralogous genes from different genomes.

Multiple alignments of each cluster were obtained by the program ClustalX [45] and T-coffee [46], followed by manual inspection and editing. Phylogenetic trees were inferred by the neighbor-joining method, using MEGA4 [47]. The inferred phylogenetic relationships were used to detect the orthologous and paralogous genes in each cluster.

\section{Functional classification analysis}

A hierarchical classification of cellular component, biological process, and molecular function was performed for each Plasmodium sequence by searching against the Gene Ontology database [48]. The classification of specific supergene families including transporters, kinases, and proteases was based on the standard nomenclature defined in the Transporter Classification (TC) system [49], the Kinase Classification System [50], and the Merops Peptidase Database [51].

Additional file 1: Core genes in six Plasmodium species $\mathrm{A}$ core genome of six Plasmodium genomes comprised of 3,351 orthologous groups is listed. Brief descriptions of predicted gene functions and $\mathrm{GO}$ functional classification are also included.

Additional file 2: Genes in Plasmodium species that show Lineage Specific Expansions (LSEs)The lineage-unique and typical LSEs are presented in the second and third spreadsheets, respectively. 


\section{List of abbreviations used}

DOXP: 1-deoxy-D-xylulose 5-phosphate; GO: Gene Ontology; GPCR: G-protein coupled receptor; LSE: lineage-specific expansion; MSP: Merozoite Surface Protein; ORF: open reading frame; PfEMP: P. falciparum erythrocyte membrane protein; RBC: red blood cell; VBEM: variational Bayesian expectation maximization; TC: Transporter Classification

\section{Acknowledgements}

We thank PlasmoDB for providing an all-in-one portal for malaria genomic data. The project described is supported by grants Al080579, GM081068, and Al067543 from the National Institute of Allergy and Infectious Diseases and National Institute of General Medical Sciences to YW. The content is solely the responsibility of the authors and does not necessarily represent the official views of the National Institute of General Medical Sciences, National Institute of Allergy and Infectious Diseases or the National Institutes of Health. JG is supported by PSC-CUNY 37 Research Award and Summer Research Award for faculty at College of Staten Island / CUNY. Publication of this supplement was made possible with support from the International Society of Intelligent Biological Medicine (ISIBM).

This article has been published as part of BMC Genomics Volume 11 Supplement 3, 2010: The full contents of the supplement are available online at http://www.biomedcentral.com/1471-2164/11?issue=S3.

\section{Author details}

'Department of Biology, University of Texas at San Antonio, San Antonio, TX 78249, USA. ${ }^{2}$ Department of Biology, College of Staten Island, City University of New York, Staten Island, NY 10314, USA. ${ }^{3}$ South Texas Center for Emerging Infectious Diseases, University of Texas at San Antonio, San Antonio, TX 78249, USA.

\section{Authors' contributions}

YW, JG, and HC conceived and designed the study. They all performed data analysis. YW and $\mathrm{HC}$ drafted the manuscript. All authors read and approved the final manuscript.

\section{Competing Interests}

The authors declare that they have no competing interests.

Published: 1 December 2010

\section{References}

1. Carlton J: The Plasmodium vivax genome sequencing project. Trends Parasitol 2003, 19(5):227-231.

2 Carlton J, Silva J, Hall N: The genome of model malaria parasites, and comparative genomics. Curr Issues Mol Biol. 2005, 7(1):23-37.

3. Carlton JM, Angiuoli SV, Suh BB, Kooij TW, Pertea M, Silva JC, Ermolaeva MD, Allen JE, Selengut JD, Koo HL, et al: Genome sequence and comparative analysis of the model rodent malaria parasite Plasmodium yoelii yoelii. Nature 2002, 419(6906):512-519.

4. Gardner MJ, Hall N, Fung E, White O, Berriman M, Hyman RW, Carlton JM, Pain A, Nelson KE, Bowman S, et al: Genome sequence of the human malaria parasite Plasmodium falciparum. Nature 2002, 419(6906):498-511.

5. Pain A, Bohme U, Berry AE, Mungall K, Finn RD, Jackson AP, Mourier T, Mistry J, Pasini EM, Aslett MA, et al: The genome of the simian and human malaria parasite Plasmodium knowlesi. Nature 2008 455(7214):799-803.

6. Peterson DS, Miller $L H$, Wellems TE: Isolation of multiple sequences from the Plasmodium falciparum genome that encode conserved domains homologous to those in erythrocyte-binding proteins. Proc Natl Acad SCi USA 1995, 92(15):7100-7104.

7. Su XZ, Heatwole VM, Wertheimer SP, Guinet F, Herrfeldt JA, Peterson DS, Ravetch JA, Wellems TE: The large diverse gene family var encodes proteins involved in cytoadherence and antigenic variation of Plasmodium falciparum-infected erythrocytes. Cell 1995, 82(1):89-100.

8. Jomaa H, Wiesner J, Sanderbrand S, Altincicek B, Weidemeyer C, Hintz M, Turbachova I, Eberl M, Zeidler J, Lichtenthaler HK, et al: Inhibitors of the nonmevalonate pathway of isoprenoid biosynthesis as antimalarial drugs. Science 1999, 285(5433):1573-1576.

9. Kuang R, Gu J, Cai H, Wang Y: Improved prediction of malaria degradomes by supervised learning with SVM and profile kernel. Genetica 2009, 136(1):189-209.
10. Wang $Y$, W $Y$ : Computer assisted searches for drug targets with emphasis on malarial proteases and their inhibitors. Curr Drug Targets Infect Disord 2004, 4(1):25-40.

11. Wu $Y$, Wang $X$, Liu $X$, Wang $Y$ : Data-mining approaches reveal hidden families of proteases in the genome of malaria parasite. Genome Res 2003, 13(4):601-616.

12. $M u J B$, Ferdig MT, Feng $X R$, Joy DA, Duan JH, Furuya T, Subramanian $G$, Aravind L, Cooper RA, Wootton JC, et al: Multiple transporters associated with malaria parasite responses to chloroquine and quinine. $\mathrm{Mol}$ Microbiol 2003, 49(4):977-989.

13. Bozdech Z, Llinas M, Pulliam BL, Wong ED, Zhu J, DeRisi JL: The transcriptome of the intraerythrocytic developmental cycle of Plasmodium falciparum. PLoS Biol 2003, 1(1):E5.

14. Bozdech Z, Mok S, Hu G, Imwong M, Jaidee A, Russell B, Ginsburg H, Nosten F, Day NP, White NJ, et al: The transcriptome of Plasmodium vivax reveals divergence and diversity of transcriptional regulation in malaria parasites. Proc Natl Acad Sci USA 2008, 105(42):16290-16295.

15. Florens L, Liu X, Wang YF, Yang SG, Schwartz O, Peglar M, Carucci D t, Yates JR, Wu YM: Proteomics approach reveals novel proteins on the surface of malaria-infected erythrocytes. Mol Biochem Parasitol 2004, 135(1):1-11.

16. Florens $L$, Washburn MP, Raine JD, Anthony RM, Grainger M, Haynes JD, Moch JK, Muster N, Sacci JB, Tabb DL, et al: A proteomic view of the Plasmodium falciparum life cycle. Nature 2002, 419(6906):520-526.

17. Hall N, Karras M, Raine JD, Carlton JM, Kooij TW, Berriman M, Florens L, Janssen CS, Pain A, Christophides GK, et al: A comprehensive survey of the Plasmodium life cycle by genomic, transcriptomic, and proteomic analyses. Science 2005, 307(5706):82-86

18. Lasonder $E$, Ishihama $Y$, Andersen JS, Vermunt AMW, Pain A, Sauerwein RW, Eling WMC, Hall N, Waters AP, Stunnenberg HG, et al: Analysis of the Plasmodium falciparum proteome by high-accuracy mass spectrometry. Nature 2002, 419(6906):537-542.

19. Le Roch KG, Zhou Y, Blair PL, Grainger M, Moch JK, Haynes JD, De La Vega P, Holder AA, Batalov S, Carucci DJ, et al: Discovery of gene function by expression profiling of the malaria parasite life cycle. Science 2003, 301(5639):1503-1508.

20. Date SV, Stoeckert CJ Jr.: Computational modeling of the Plasmodium falciparum interactome reveals protein function on a genome-wide scale. Genome Res 2006, 16(4):542-549.

21. LaCount DJ, Vignali M, Chettier R, Phansalkar A, Bell R, Hesselberth JR, Schoenfeld LW, Ota I, Sahasrabudhe S, Kurschner C, et al: A protein interaction network of the malaria parasite Plasmodium falciparum. Nature 2005, 438(7064):103-107.

22. Llinas M, Bozdech Z, Wong ED, Adai AT, DeRisi JL: Comparative whole genome transcriptome analysis of three Plasmodium falciparum strains. Nucleic Acids Res 2006, 34(4):1166-1173.

23. Cox-Singh J, Davis TM, Lee KS, Shamsul SS, Matusop A, Ratnam S, Rahman HA, Conway DJ, Singh B: Plasmodium knowlesi malaria in humans is widely distributed and potentially life threatening. Clin Infect Dis 2008, 46(2):165-171.

24. Callebaut I, Prat K, Meurice E, Mornon JP, Tomavo S: Prediction of the general transcription factors associated with RNA polymerase II in Plasmodium falciparum: conserved features and differences relative to other eukaryotes. BMC Genomics 2005, 6:100.

25. Wu J, Sieglaff DH, Gervin J, Xie XS: Discovering regulatory motifs in the Plasmodium genome using comparative genomics. Bioinformatics 2008, 24(17):1843-1849.

26. Young JA, Johnson JR, Benner C, Yan SF, Chen K, Le Roch KG, Zhou Y, Winzeler EA: In silico discovery of transcription regulatory elements in Plasmodium falciparum. BMC Genomics 2008, 9:70

27. Doerig C, Meijer L, Mottram JC: Protein kinases as drug targets in parasitic protozoa. Trends Parasitol 2002, 18(8):366-371.

28. Rangarajan R, Bei A, Henry N, Madamet M, Parzy D, Nivez MP, Doerig C, Sultan A: Pbcrk-1, the Plasmodium berghei orthologue of $P$. falciparum cdc-2 related kinase-1 (Pfcrk-1), is essential for completion of the intraerythrocytic asexual cycle. Exp Parasitol 2006, 112(3):202-207.

29. Reininger L, Billker O, Tewari R, Mukhopadhyay A, Fennell C, DorinSemblat D, Doerig C, Goldring D, Harmse L, Ranford-Cartwright L, et al: A NIMA-related protein kinase is essential for completion of the sexual cycle of malaria parasites. J Biol Chem 2005, 280(36):31957-31964. 
30. Tienda-Luna IM, Yin Y, Carrion MC, Huang Y, Cai H, Sanchez M, Wang Y: Inferring the skeleton cell cycle regulatory network of malaria parasite using comparative genomic and variational Bayesian approaches. Genetica 2008, 132(2):131-142.

31. Harrison T, Samuel BU, Akompong T, Hamm H, Mohandas N, Lomasney JW, Haldar K: Erythrocyte $\mathrm{G}$ protein-coupled receptor signaling in malarial infection. Science 2003, 301(5640):1734-1736.

32. Pachebat JA, Kadekoppala M, Grainger M, Dluzewski AR, Gunaratne RS, Scott-Finnigan TJ, Ogun SA, Ling IT, Bannister LH, Taylor HM, et al: Extensive proteolytic processing of the malaria parasite merozoite surface protein 7 during biosynthesis and parasite release from erythrocytes. Mol Biochem Parasitol. 2007, 151(1):59-69.

33. Fanning SL, Czesny B, Sedegah M, Carucci DJ, van Gemert GJ, Eling W, Williamson KC: A glycosylphosphatidylinositol anchor signal sequence enhances the immunogenicity of a DNA vaccine encoding Plasmodium falciparum sexual-stage antigen, Pfs230. Vaccine 2003, 21(23):3228-3235.

34. Kooij TW, Carlton JM, Bidwell SL, Hall N, Ramesar J, Janse CJ, Waters AP: Plasmodium whole-genome synteny map: indels and synteny breakpoints as foci for species-specific genes. PLoS Pathog 2005, 1(4):e44.

35. Sargeant TJ, Marti M, Caler E, Carlton JM, Simpson K, Speed TP, Cowman AF: Lineage-specific expansion of proteins exported to erythrocytes in malaria parasites. Genome Biol 2006, 7(2):R12.

36. Cheng Q, Cloonan N, Fischer K, Thompson J, Waine G, Lanzer M, Saul A: stevor and rif are Plasmodium falciparum multicopy gene families which potentially encode variant antigens. Mol Biochem Parasitol 1998, 97(12):161-176.

37. Joannin N, Abhiman S, Sonnhammer EL, Wahlgren M: Sub-grouping and sub-functionalization of the RIFIN multi-copy protein family. BMC Genomics 2008, 9:19.

38. Hernandez-Rivas R, Hinterberg K, Scherf A: Compartmentalization of genes coding for immunodominant antigens to fragile chromosome ends leads to dispersed subtelomeric gene families and rapid gene evolution in Plasmodium falciparum. Mol Biochem Parasitol 1996, 78(1-2):137-148.

39. Robinson BA, Welch TL, Smith JD: Widespread functional specialization of Plasmodium falciparum erythrocyte membrane protein 1 family members to bind CD36 analysed across a parasite genome. Mol Microbiol 2003, 47(5):1265-1278.

40. del Portillo HA, Fernandez-Becerra C, Bowman S, Oliver K, Preuss M, Sanchez CP, Schneider NK, Villalobos JM, Rajandream MA, Harris D, et al: A superfamily of variant genes encoded in the subtelomeric region of Plasmodium vivax. Nature 2001, 410(6830):839-842.

41. del Portillo HA, Lanzer M, Rodriguez-Malaga S, Zavala F, FernandezBecerra C: Variant genes and the spleen in Plasmodium vivax malaria. Int J Parasitol 2004, 34(13-14):1547-1554.

42. Aurrecoechea C, Brestelli J, Brunk BP, Dommer J, Fischer S, Gajria B, Gao X Gingle A, Grant G, Harb OS, et al: PlasmoDB: a functional genomic database for malaria parasites. Nucleic Acids Res 2009, 37(Databaseissue): D539-543.

43. Gu Z, Cavalcanti A, Chen FC, Bouman P, Li WH: Extent of gene duplication in the genomes of Drosophila, nematode, and yeast. Mol Biol Evol 2002, 19(3):256-262.

44. Li L, Stoeckert CJ Jr., Roos DS: OrthoMCL: identification of ortholog groups for eukaryotic genomes. Genome Res 2003, 13(9):2178-2189.

45. Thompson JD, Gibson TJ, Higgins DG: Multiple sequence alignment using ClustalW and ClustalX. Curr Protoc Bioinformatics 2002, Chapter2:Unit23.

46. Notredame C, Higgins DG, Heringa J: T-Coffee: A novel method for fast and accurate multiple sequence alignment. J Mol Biol 302(1): 205-217.

47. Kumar S, Nei M, Dudley J, Tamura K: MEGA: a biologist-centric software for evolutionary analysis of DNA and protein sequences. Brief Bioinform 2008, 9(4):299-306.

48. Ashburner M, Ball CA, Blake JA, Botstein D, Butler H, Cherry JM, Davis AP, Dolinski K, Dwight SS, Eppig JT, et al: Gene ontology: tool for the unification of biology. The Gene Ontology Consortium. Nat Genet 2000, 25(1):25-29.

49. Saier MH Jr., Tran CV, Barabote RD: TCDB: the Transporter Classification Database for membrane transport protein analyses and information. Nucleic Acids Res 2006, 34(Databaseissue):D181-186.

50. Cheek S, Ginalski K, Zhang H, Grishin NV: A comprehensive update of the sequence and structure classification of kinases. BMC Struct Biol 2005, 5:6.

51. Rawlings ND, Morton FR, Kok CY, Kong J, Barrett AJ: MEROPS: the peptidase database. Nucleic Acids Res 2008, 36(Databaseissue):D320-325.
doi:10.1186/1471-2164-11-S3-S13

Cite this article as: Cai et al:: Core genome components and lineage specific expansions in malaria parasites Plasmodium. BMC Genomics 2010 11(Suppl 3):S13.

\section{Submit your next manuscript to BioMed Central and take full advantage of:}

- Convenient online submission

- Thorough peer review

- No space constraints or color figure charges

- Immediate publication on acceptance

- Inclusion in PubMed, CAS, Scopus and Google Scholar

- Research which is freely available for redistribution 